Article

\title{
Study of the School-Residence Spatial Relationship and the Characteristics of Travel-to-School Distance in Shenyang
}

\author{
Dawei Mei ${ }^{1}$, Chunliang Xiu ${ }^{2, *}$, Xinghua Feng ${ }^{1}$ and Ye Wei ${ }^{1}$ (I) \\ 1 School of Geographical Sciences, Northeast Normal University, Changchun 130024, Jilin, China \\ 2 College of Jang Ho Architecture, Northeastern University, Shenyang 110169, Liaoning, China \\ * Correspondence: xiuchunliang@mail.neu.edu.cn; Tel.: +86-189-4318-9011
}

Received: 17 July 2019; Accepted: 13 August 2019; Published: 16 August 2019

\begin{abstract}
The school-residence spatial relationship is a key factor in understanding urban spatial structure and travel-to-school behavior of students. Analyzing the change law and the spatial characteristics of travel-to-school distance can provide a basis for improved accessibility of urban educational facilities and enable enrolment of students from the neighborhood. Based on one complete month of mobile phone signaling data for May 2018, the changes in student density with the travel-to-school distance was analyzed using MATLAB and Mann-Kendall Trend Test, and the pattern and the spatial structure of travel-to-school were explored. The results revealed that: (1) With increase in travel-to-school distance, the student density showed a decrease in truncated power law distribution, and it is concentrated within the travel-to-school distance of $5.0 \mathrm{~km}$; (2) According to the sudden change points of the student density growth rate, the threshold distance for travel to kindergartens is $1.30 \mathrm{~km}$, and for primary schools and secondary schools is $1.50 \mathrm{~km}$. The school-residence spatial structure is divided according to the threshold of travel-to-school distance and the scope of attendance; (3) The dominant flow of travel-to-school is generally from urban peripheral and marginal areas to the urban core area, and partly from marginal areas to peripheral areas; (4) The pattern of travel-to-school is polycentric, and the study centers are mainly located in the urban central district north of the Hun River. The urban core area has the strongest attraction of students, while the marginal area has the weakest.
\end{abstract}

Keywords: Mann-Kendall; school-residence spatial relationship; mobile phone signaling data; travel-to-school distance; Shenyang

\section{Introduction}

The spatial relationship between schools and residences, and the resulting travel-to-school behavior has an important impact on the functional layout of a city, which is also one of the important reasons for the morning and evening peak traffic in cities. In addition, the "space imbalance" between schooling demand and supply has caused urban residents to bear higher costs in terms of time and money to enjoy corresponding public services, which has also led to an increase in social and economic costs. Lu et al. found that driving children to schools across districts accounts for about $15 \%$ of the traffic flow of motor vehicles during the morning rush hours in Beijing [1]. Such traffic leads to an increase in the degree of road congestion by about $20 \%$ and increases the air pollution in the city. According to Zheng et al., house prices in a good education district were $8.1 \%$ higher than those in other districts in 2011 [2]. In China, schools are often associated with "school districts", which correspond to residences within a geographical area of the school districts and provide schooling for students living within that area. Establishment of school districts aims to achieve the closest 
distance from residences to schools and ensure enrollment of neighborhood children in the compulsory education stage, allowing students to walk to schools [3]. However, school districts have been unable to discourage parents and students from choosing schools that are far from their homes. In particular, pursuit of high-quality basic education resources has led to the widespread phenomenon of choosing cross-district schools, resulting in long-distance travel to schools. Due to the uneven distribution of high-quality educational resources, pursuit of high-quality education resources has been a decisive factor in the increase in distance between residences and schools, which has further aggravated the urban traffic problem [4]. Therefore, the focus of urban functional relationship research should be on the school-residence spatial relationship and travel-to-school behavior, which is related to orderly organization of urban functional activities and urban sustainable development.

Before the 1960s, Western scholars in modern times performed research on the planning theory of educational facilities. For example, Howard developed the theory of "garden cities", in which he embodied the idea of integrating the school into the place of residence [5]. Since the 1960s, there have been studies about allocation of basic education resources and the layout of educational facilities. Based on the location theory of public facilities, $\mathrm{O}^{\prime}$ Brien et al. constructed an econometric model to create a school layout with spatial balance of efficiency and fairness as the core goal $[6,7]$, placing emphasis on the convenience of students traveling to schools. Early studies on the allocation of educational resources and the layout of educational facilities mainly focus on students. Later, the focus group expanded from students to government education departments, schools, teachers, and other related groups. The research focused on the topics of the relationship between the layout of educational resources and residential differentiation [8], public housing and schooling [9], and community-school segregation [10-12]. Lange et al. constructed a spatial index of educational opportunities by studying the educational needs of school-age children and the number of local schools in two large cities in Brazil [13]. The result was that differences in urban educational policies affect the overall spatial distribution of educational opportunities. Wu et al. proposed the concept of "Jiaoyufication"-a concept of social space in the interior cities of China [14,15]. Yang et al. analyzed the formation process of school districts or educational space and its relationship with urban social space from the perspective of externality of the school district [16]. The distribution of high-quality school resources can also affect housing prices and has an important impact on residents' lives [17-20].

Creating a good environment for children to travel to school has also become an urgent problem when it comes to urban transportation, planning, and management. Researchers began to study the travel-to-school behavior of children in Western countries in the 1980s, and one of the earliest interventions was in the area of public health. They believed that the decline of active travel (walking and cycling) was one of the factors that led to a decline in physical activity among children, which in turn led to an increase in obesity rates. It was believed that physical activity could be promoted by improving the infrastructure environment [21,22]. In the field of transportation and urban planning, the study of adult travel behavior has gradually begun to focus on travel-to-school behavior of children. Factors that affect travel-to-school behavior are analyzed from the aspects of transportation management policy and infrastructure environment. These include the choice of transportation modes and their relationship with health, safety, environment, and school layout [23,24]. Bouzarth et al. provided a series of different school choice methods by using parametric models, which can be used as a reference for decision-makers to balance socioeconomic factors and distance costs [25]. Müller et al. found that distance, car ownership, and weather conditions were the main factors that led to parents driving their children to schools [26]. Larsen et al. studied the effects of physical environment and socio-demographic characteristics on the choice of school transportation mode for children [27]. Andersson et al. studied the differences in school attendance among different groups and regions, based on the changes in school distance of Swedish students from 2000 to 2006. They found that there were more spatial and temporal constraints among families with fewer resources [28]. In addition, Cheng et al. analyzed the relationship between excessive residence-kindergarten commute and their spatial mismatch and explored the reasons for excessive commute [29]. Boussauw et al. simulated a large 
number of home-school trajectories and examined the relationship of home-school distances and spatial distribution of the school sites [30]. Easton et al. verified that students' behavior when traveling to school was influenced by individuals, communities, and schools [31]. Marique et al. found that school commuting was related to energy consumption, travel distances, and mode choices [32]. Therefore, the study of traveling to schools involves many aspects, such as urban transportation, residents' travel costs, and urban space utilization. However, previous studies mainly focused on the relationship between traveling to schools and the built environment, the choice of travel mode, school distance, and residential location, and only a few studies have researched the spatiotemporal school-residence structure [33]. In addition, previous studies were mainly based on data from questionnaires, traffic surveys, and other surveys. Consequently, there are few studies on the relationship between residences and schools and the characteristics of school distance. Therefore, it is necessary to analyze the school-residence relationship, and the law of the travel-to-school distance, so as to optimize the spatial structure of living and schooling.

In recent years, the use of Metro cards, smartphones, bus smart cards, check-ins, and taxi tracking for acquiring widely representative resident activity data has become a hot research topic internationally [34-38]. In particular, mobile phone signaling data has wide network coverage, data stability and reliability, a large number of samples, high spatial resolution, strong dynamics, and other advantages that can report on the situation of urban travel [39,40]. Therefore, using mobile signaling data, combined with the corresponding model algorithm processing, the travel characteristic data can be extracted to analyze the residents' travel characteristics [41,42]. Using mobile phone signaling data to analyze travel characteristics has become the focus of academic research, and there has been some progress in related research in the job-housing spatial structure and commute of residents [43,44]. However, although the school-residence relationship in Chinese cities is an academic issue with urban characteristics, few related researches have been done, even in the era of Big Data. Hence, the school-residence relationship is innovative content in the research of functional urban relationships. As the largest central city in northeast China, Shenyang has experienced rapid urban expansion, which is consistent with the rapid expansion of major cities in the country. Spatially, as the main city on the north bank of the Hun River, it extends in all directions and is characterized by a single central ring with surrounding expansion. The growth in supporting public service facilities lags with respect to the speed of urban expansion. In addition, since the 1990s, commercial housing construction led by real estate developers has become the mainstay of the urban housing supply, with many new commercial housing construction sites being concentrated in the suburbs. Construction of urban transportation infrastructure and motorization of private transportation has also promoted suburbanization of the urban living space. Due to suburbanization, there is a low density of urban construction and residential population, leading to a lack of basic education facilities and excessive travel distance to schools. There is an urgent need to study the spatial relationship between schools and residences in Shenyang, in order to provide reference for rational allocation of basic educational resources.

Above all, this study intends to answer four important questions: (1) What is the relationship between student density and travel-to-school distance, and what is the attraction range of basic education facilities to students in Shenyang? (2) What is the threshold of travel-to-school distance for basic education in Shenyang and what are the characteristics of the school-residence spatial structure? (3) What is the overall pattern of the travel-to-school distance for basic education in Shenyang and what are the characteristics of the leading flow direction of traveling to schools? (4) What are the school centers in Shenyang and how are the school centers distributed? Based on the above knowledge, this study uses mobile phone signaling OD data of May 2018 to explore the characteristics of travel-to-school distance and the school-residence relationship in the downtown area of Shenyang. Consequently, it can provide reference for allocation of living and studying space in Shenyang that can ensure neighborhood students can enroll in the schools. 


\section{Study Area, Data, and Methods}

\subsection{Study Area}

Located in the northeastern part of the country and in central Liaoning, Shenyang is an important city that is the capital and subprovince-level division of Liaoning Province. The study area includes all or major parts of the nine urban areas, such as Shenhe District, Heping District, Tiexi District, Huanggu District, Dadong District, Hunnan District, Yuhong District, Sujiatun District, and Shenbei New District. It includes 96 streets, basically covering the major functional areas of the city, with a total area of 1254.88 square kilometers. The travel-to-school behavior of students in the study includes kindergartens, primary schools, and secondary schools (including junior and senior middle schools). The school data was from points of interest data (POI) of educational facilities of Shenyang in 2018. The number of kindergartens, primary schools, and secondary schools is 2511, 365, and 252 respectively. The study area and distribution of schools is shown in Figure 1.

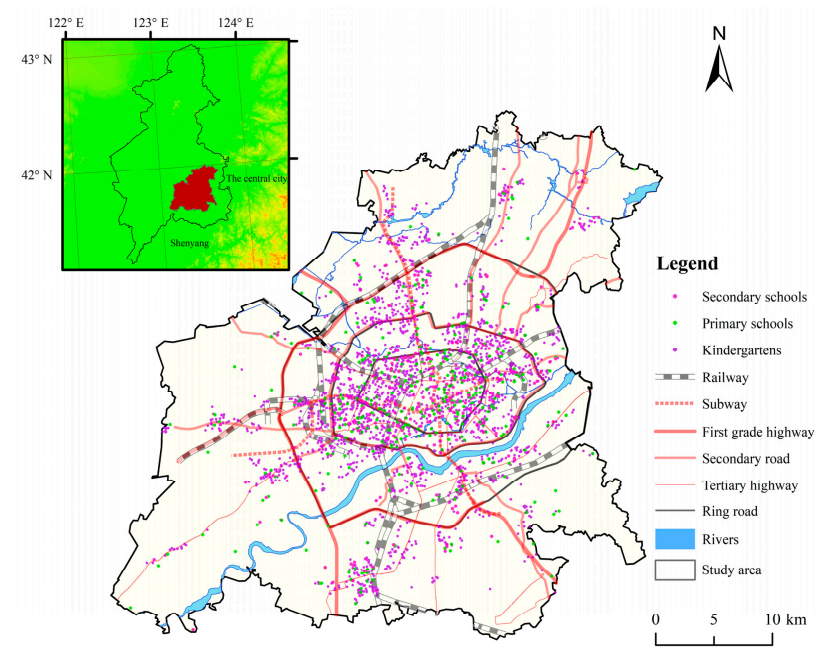

Figure 1. Survey of the study area and distribution of schools.

\subsection{Data}

Mobile terminals regularly or irregularly, actively or passively maintain contact with the mobile communication network, and are identified by a series of control commands, i.e., mobile signaling. The data of this study was derived from the mobile phone signaling data of Unicom users in Shenyang for a month in May 2018. It includes the encrypted unique user identification number (anonymous number, no personal information), type of signaling, time when the signaling occurs, base station connected to the mobile phone when the signaling occurs, etc. It does not include the purpose of user activities and does not directly access behavioral characteristics such as residence, schooling, etc. By analyzing the original mobile phone signaling data and taking into account the general rules of traveling to school, we established rules to identify the places of residence of students who use mobile phones. (1) Residence observation period: from 21:00 to 8:00 the next day. (2) The number of seconds the user is observed during the observation period is captured on a monthly basis and ranked. The highest ranking indicates the residence of the user. (3) The number of days in a month exceeds 2 weeks. The travel-to-school behaviors are identified as follows: the signaling data of resident users recorded in the school circle (200 m) from 6:00-10:00 in the morning and 15:00-19:00 in the afternoon on weekdays; these users are considered to have visited the school on that day. Users who appear in their residence on weekdays are considered to be at home that day. Users who are both at home and at school for more than 10 weekdays in a month are considered to exhibit travel-to-school behavior. 


\subsection{Methodology}

\subsubsection{Mann-Kendall Trend Test}

The Mann-Kendall trend test is a nonparametric statistical test method, which has the advantages of a wide test range, limited artificial influence, and high quantitative degree. In the Mann-Kendall Trend Test, two normal distribution statistics, $U F_{i}$ and $U B_{i}$, are constructed according to the distance series, and then a statistical chart of the curve is drawn to judge the mutation point and the region. If the value of $U F$ or $U B$ is greater than 0 , it indicates an upward trend in the time series, whereas if the value is less than 0 , it indicates a downward trend. When they exceed a critical straight line (a given level of significance), there is a marked upward or downward trend. The range beyond the critical line is defined as the zone in which the mutation occurs. If there is a point of intersection of the two curves $U F$ and $U B$, and the point of intersection is between the critical straight lines, then the point of intersection corresponds to the distance at which the mutation begins.

\subsubsection{Travel-to-School Measurement Methods}

(1) Average Travel-to-School Distance

Average travel-to-school distance is the average of all students in a certain area, and the distance is the straight-line distance between residences and schools. The study area is divided into several grids of $0.5 \mathrm{~km} \times 0.5 \mathrm{~km}$, and $Z$ is a set of all grids; if the area $I$ contains several grids, then the average distance of travel to school in the area $I$ is as follows:

$$
D_{I}=\frac{\sum_{i \in I, j \in Z} c_{i j} d_{i j}}{\sum_{i \in I, j \in Z} c_{i j}}
$$

In the formula, $D_{I}$ represents the average distance traveled by students in the area $I, c_{i j}$ indicates the number of people living in the grid $i$, enrolled in schools in the grid $j, d_{i j}$ is the shortest path distance from the grid $i$ to the grid $j$.

(2) Travel-to-School Direction Measurement

Analyzing the flow of the travel-to-school direction of students and identifying the spatial pattern of the travel-to-school of the students in the central city of Shenyang, based on the number of students residing and studying in different regions and in the same region, the in and out of travel-to-school rates for different regions were calculated, as follows:

$$
\begin{gathered}
C_{e}=\frac{N_{h}-N_{h s}}{N_{h}} \\
C_{i}=\frac{N_{s}-N_{h s}}{N_{s}}
\end{gathered}
$$

In the formula: $C_{e}$ and $C_{i}$ are the out and in of travel-to-school rates, respectively; $N_{h}$ is the number of students living in a region; $N_{S}$ is the number of students studying in a region; $N_{h s}$ is the number of students living and studying in a region.

\section{Analysis of Travel-to-School Distance}

\subsection{Fitting Analysis of Change in Student Density with Distance}

According to the rules above, 237,997 kindergartners, 51,045 primary school students, and 32,450 secondary school students were identified as having travel-to-school behavioral characteristics in the study area. Student density and distance of all kindergartens, primary schools, and middle schools were statistically analyzed to explore the change law of the student density with distance. Taking each school as the center and taking $0.1 \mathrm{~km}$ as the radius, the student density in the range of $0.1 \mathrm{~km}$ was successively counted, and MATLAB software was used to figure out the optimal function model of 
student density and travel-to-school distance (Figure 2). The relationship of the density of students in kindergarten, primary, and secondary schools $(\mathrm{y})$ with travel-to-school distance $(\mathrm{x})$ was obtained. According to the results, student density presents a truncated decreasing power law distribution. When the distance reaches $5 \mathrm{~km}$, the attenuation rate of student density becomes smooth. The student density in the $5 \mathrm{~km}$ radius constitutes $80 \%$ of the total, which indicates that the $5 \mathrm{~km}$ range is the attraction area of the students. The student density is very low beyond $5 \mathrm{~km}$. The student density of kindergartens, primary schools, and secondary schools with school distance are similar, and the change law of student density with distance can provide a reference for school-residence spatial distribution.
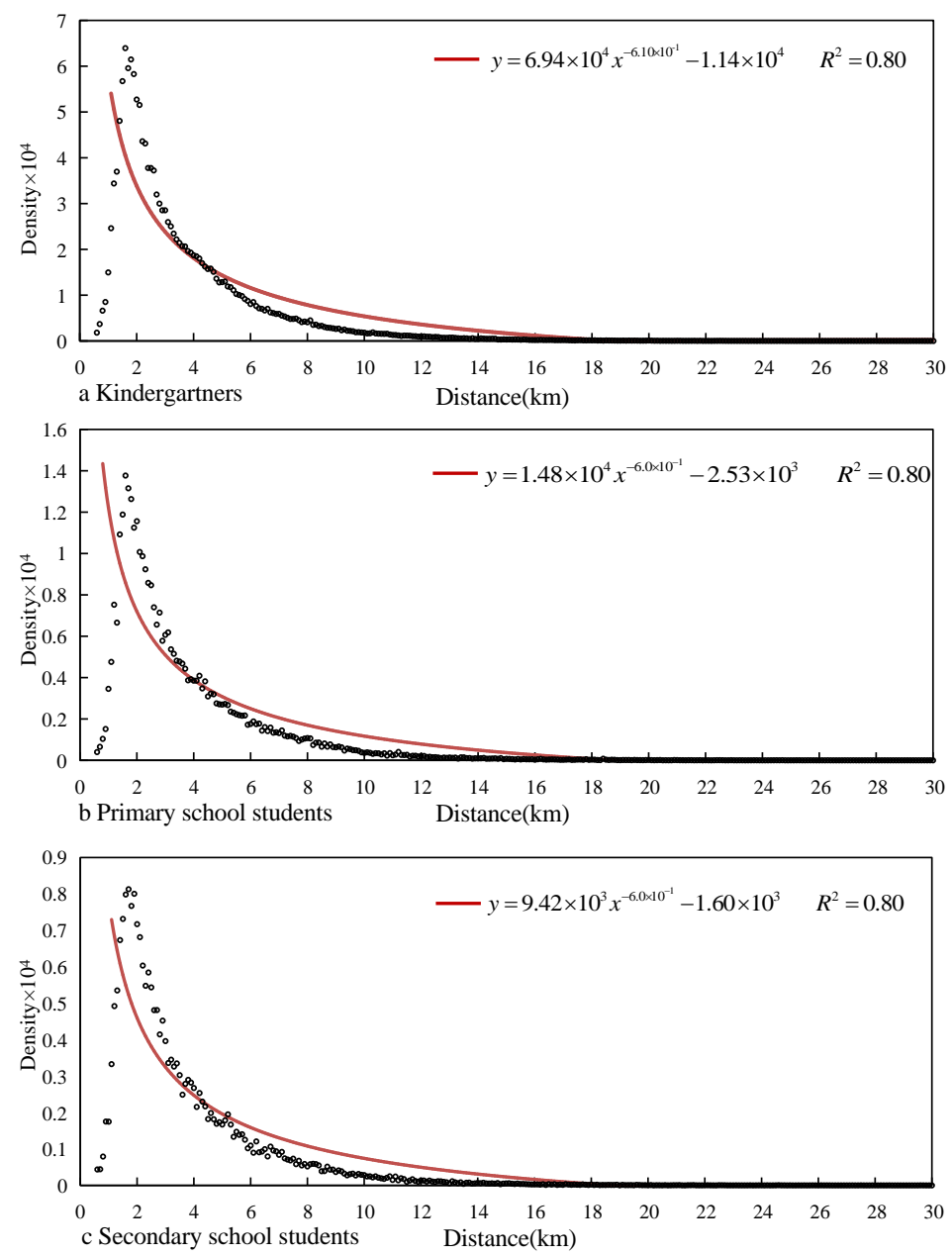

Figure 2. Relationship between density of students attending school and the distance. (Note: Number of students who live more than $30 \mathrm{~km}$ away from the school is very small, hence the figure only extends to $30 \mathrm{~km})$.

\subsection{Judging the Distance Threshold of Student Density}

In order to further judge the threshold of travel-to-school distance within the concentration range of student density, the distance series data of the student density increase rate for 0-5 km was selected, given the significance level of 0.05 . The mutation nodes were detected, and the Mann-Kendall statistic curve drawn (Figure 3). For the kindergarten-residence distance, the growth rate of student density within $0-0.6 \mathrm{~km}$ is on the decline, and it fluctuates and increases from $0.6 \mathrm{~km}$ to $1.1 \mathrm{~km}$. There is a significant decrease after $1.1 \mathrm{~km}$, and it exceeds the 0.05 significance level in some distance nodes. $U F$ and $U B$ are two statistics which conform to a normal distribution, and form two series change curves. According to the intersection point of the $U F$ and $U B$ curves, the first mutation point is located at $1.30 \mathrm{~km}$, and similarly, the first mutation point of primary schools and secondary schools is 
located at $1.50 \mathrm{~km}$. Therefore, the distance thresholds for kindergartens is $1.30 \mathrm{~km}$, and for primary and secondary schools it is at $1.50 \mathrm{~km}$. The growth rate of student density decreases significantly beyond this threshold; therefore, travel-to-school behavior within the range of the distance threshold is "near-school enrollment".
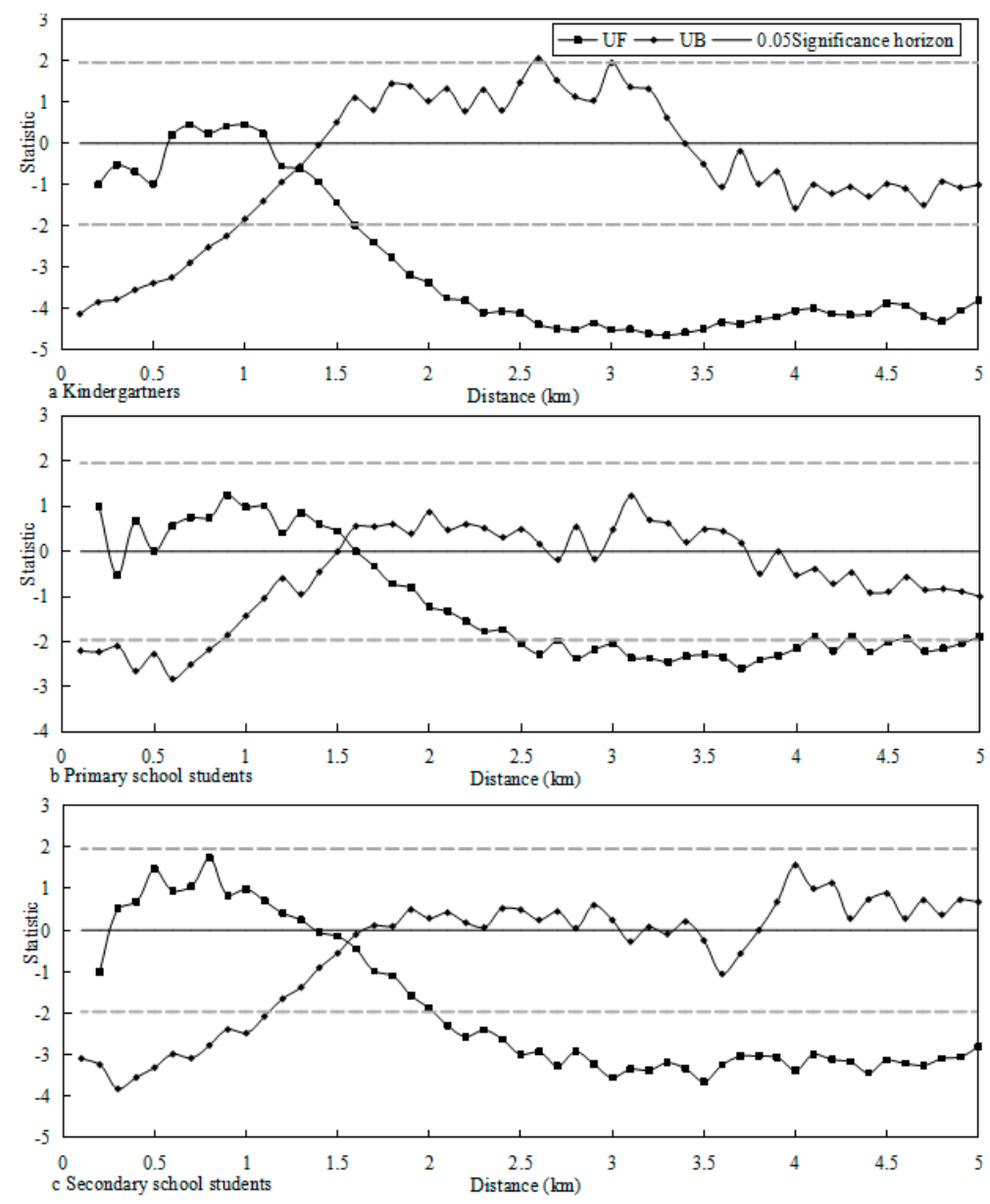

Figure 3. Mann-Kendall statistical curve of the growth rate of student enrollment.

\subsection{Spatial Structure of Schools and Residences}

The number of students inside the threshold were counted. Considering the coverage area of base stations in the central city and average distance between base stations, a kernel density analysis with a search radius of $1.0 \mathrm{~km}$ in ArcGIS 10.5 was carried out to visualize the distribution of kindergartners, primary school students, and secondary school students. Because the clustered distribution of the minimum critical value of nuclear density is 100 , several discrete blocks are formed when the student density is less than that. Therefore, the distribution of students in kindergartens, primary schools, and secondary schools with nuclear density higher than 100 is visualized (Figure 4). The spatial structure of travel-to-school distance was divided according to student density within the threshold distance. The short-distance schooling area is defined as the shortest range within the distance threshold, in which the travel-to-school distance of kindergartners is less than $1.3 \mathrm{~km}$, and that of primary school students and secondary school students is less than $1.5 \mathrm{~km}$. It is located in the urban core area, including Heping District, Shenhe District, and Dadong District, and it is the most densely distributed area of students; the number of students in kindergartens, primary schools, and secondary schools accounts for $84.19 \%, 85.48 \%$, and $79.01 \%$ of the total, respectively. The medium-distance schooling area is within the scope of schooling attraction; the travel-to-school distance of kindergartners is between $1.3 \mathrm{~km}$ and $1.5 \mathrm{~km}$, and for primary school students and secondary school students it is between $1.5 \mathrm{~km}$ and $5.0 \mathrm{~km}$. 
This area is located in the urban peripheral area, including partial areas of Heping District, Dadong District, Huanggu District, and Tiexi District. The proportion of students in kindergartens, primary schools, and secondary schools is $14.69 \%, 11.30 \%$, and $16.06 \%$ in the medium-distance schooling area, respectively. The long-distance schooling area is the area outside the attraction scope of schooling; the school distances are more than $5.0 \mathrm{~km}$, and it is mainly in the urban marginal area.

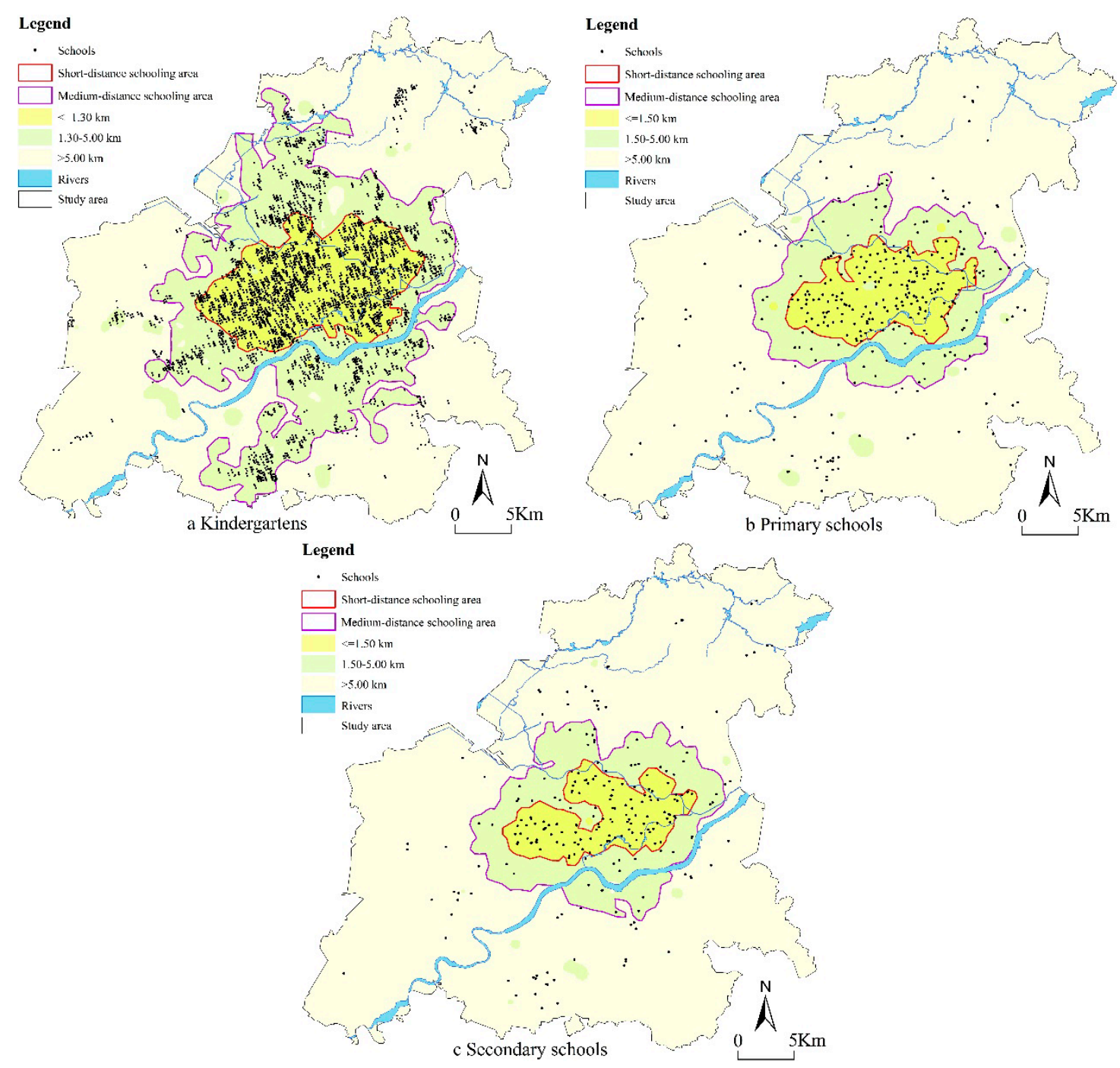

Figure 4. Spatial structure characteristics of residence-school distance.

It is worth noting that the student density of residences and schools north of Hunhe River is obviously higher than that in the south, which indicates that Hunhe River has a great impact on the layout of urban educational facilities. There is a great difference in school-residence ratio in different regions, and in the short-distance schooling area, it is obviously higher than in the medium-distance and long-distance schooling areas. Indicators of school-residence distance in each region are shown in Table 1. According to the formula (1), the average distance of traveling to kindergartens, primary schools, and secondary schools is $5.52 \mathrm{~km}, 5.54 \mathrm{~km}$, and $5.55 \mathrm{~km}$ in the study area, and the standard deviation is $4.80 \mathrm{~km}, 4.62 \mathrm{~km}$, and $4.72 \mathrm{~km}$, respectively. 
Table 1. Comparison of school-residence indexes in different areas.

\begin{tabular}{ccccccc}
\hline & \multicolumn{2}{c}{ Proportion of School-Residence } & \multicolumn{3}{c}{ Average Distance of Traveling to Schools/km } \\
\cline { 2 - 7 } & Kindergartens & $\begin{array}{c}\text { Primary } \\
\text { Schools }\end{array}$ & $\begin{array}{c}\text { Secondary } \\
\text { Schools }\end{array}$ & Kindergartens & $\begin{array}{c}\text { Primary } \\
\text { Schools }\end{array}$ & $\begin{array}{c}\text { Secondary } \\
\text { Schools }\end{array}$ \\
\hline $\begin{array}{c}\text { Short-distance } \\
\text { schooling area }\end{array}$ & 1.30 & 1.49 & 1.43 & 4.34 & 4.10 & 4.16 \\
$\begin{array}{c}\text { Medium-distance } \\
\text { schooling area }\end{array}$ & 0.49 & 0.32 & 0.42 & 6.58 & 6.85 & 6.78 \\
$\begin{array}{c}\text { Long-distance } \\
\text { schooling area }\end{array}$ & 0.27 & 0.23 & 0.30 & 10.77 & 12.07 & 13.47 \\
\hline
\end{tabular}

\section{Spatial Structure Characteristics of Travel-to-School}

To better describe the dominant direction and volume of travel to schools in the study area, the travel-to-school flow was summarized and visualized at a grid scale of $0.5 \mathrm{~km}$ (Figure 5). The number of travel-to-school links for kindergartens, primary schools, and secondary schools are 93,861, 28,191, and 20,829, and the volume is 3,583,500,774,000, and 490,900, respectively. According to the head-tail division proposed by Jiang and Liu [45], the number of students traveling to schools is divided into seven levels, and high-level links of travel to school are visualized to depict dominant trips. There are 620, 467, and 181 links among the corresponding research units in kindergartens, primary schools, and secondary schools from level 5 to level 7 , accounting for $0.61 \%, 1.49 \%$, and $0.87 \%$ of the total links, respectively. The number of students traveling to schools is $245,100,67,100$, and 31,500 , accounting for $6.84 \%, 8.67 \%$, and $6.41 \%$, respectively, indicating that some trip links carry more trips, reflecting the main travel pattern of the whole region.

In order to further understand the main characteristics of traveling to schools, the first three levels are elaborated in detail. The ratios of the number of students and the links in corresponding units of kindergartens, primary, and secondary schools at level 7 are 966.68, 299.68, and 397.50, respectively. This indicates that the travel-to-school flow is relatively concentrated at this level. The 7th level travel-to-school pattern is mainly the connection between key schools and the adjacent important residential areas in the short-distance schooling area. The reason is that these are the functional center of the urban economy and culture, rich in high-quality education resources which attract a large number of students. Although a small amount of cross-regional traveling to schools is included in level 7-for example, a lot of students in Sujiatun District also attend Hunnan Four-school kindergarten and Tongxin Bilingual kindergarten in Hunnan District-the data is not as strong as the former. There are several possible reasons for the phenomenon of long-distance travel to schools across regions: Firstly, parents choose schools in or near their place of employment in order to facilitate transportation of their children. Secondly, pursuit of quality educational resources by parents or students leads to cross-regional schooling. Thirdly, separation of place of origin from the schools is also caused by living and attending schools in the current place of residence in the city center during the working day and returning to the original place of residence in the suburbs on weekends.

The ratio of the number of students and links at level 6 are 470.71,186.82, and 227.00, respectively, and the school flow is relatively concentrated. The hierarchy is mainly composed of key schools and important residential areas within the short-distance schooling area, and between the short-distance and medium-distance schooling areas. Cross-regional school attendance increased significantly compared to level 7; for example, some students in Shenbei New District attend schools in districts where quality education resources are concentrated, such as Heping District and Shenhe District. The ratios at level 5 are 300.95, 122.66, and 135.26, respectively. Travel-to-school flow runs from short-distance schooling areas to long-distance schooling areas. It forms a small-scale intensive travel flow in the old urban areas of Heping District, Shenhe District, Dadong District, and Tiexi District, and the number of students attending schools increased from the fringe districts of Shenbei New District, Sujiatun District, and Hunnan District to the central districts. On the whole, dominant travel-to-school flow is generally inward to the short-distance schooling area, partly concentrated from the medium-distance 
and long-distance schooling area to the short-distance schooling area, and a small amount is the travel flow between the medium-distance and long-distance schooling areas.
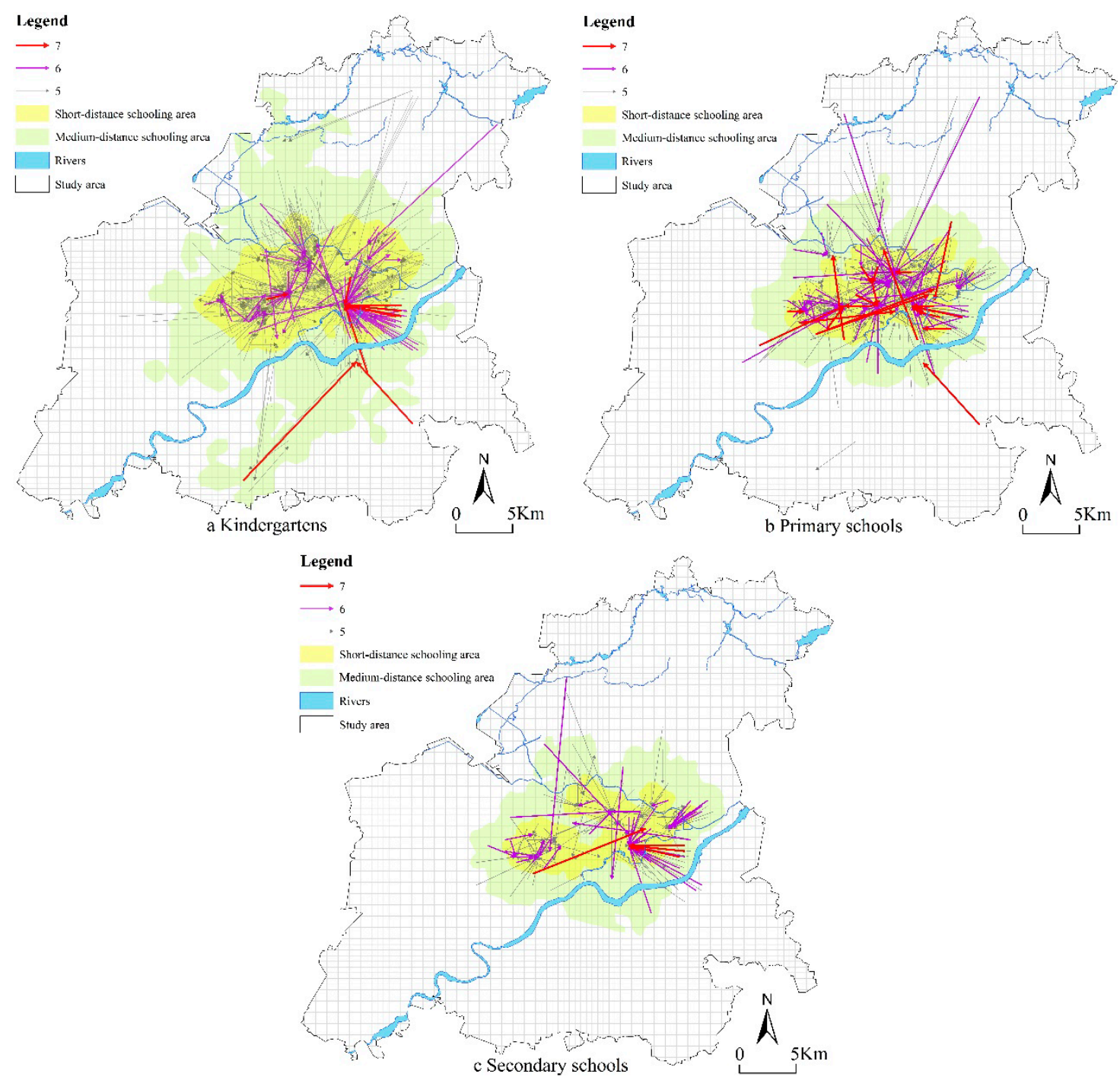

Figure 5. Travel-to-school links at $0.5 \mathrm{~km}$ grid scale.

The school-residence index can directly explain the flow characteristics and direction between the different schooling areas of students identified using cell phone signaling data (Table 2), and it can better explain the characteristics of travel to school. According to the characteristics of schools and residences, most of the demand for schooling is in the short-distance and medium-distance schooling areas. The pressure of schooling in the short-distance area is greater than that for residences, while the residential pressure is greater than that of schooling in the medium-distance area. There are few students who travel to the long-distance schooling area, and those who do mainly live there. According to Formulas (2) and (3), we have calculated the travel-to-school rate of the three regions as $12.58 \%, 4.80 \%$, and $5.65 \%$ of kindergartners, primary, and secondary school students who live in the short-distance schooling area. The proportion of students entering the short-distance schooling are was $33.86 \%, 34.53 \%$, and $34.15 \%$, respectively. The in-going and out-going school attendance rates in the medium-distance schooling area are similar. The out-going school attendance rate in the long-distance schooling area is much higher than the in-going rate. In addition, among the students living and studying in the short-distance and medium-distance schooling areas, the students studying in the short-distance schooling area mainly live in that area. The out-going and in-going school attendance 
rate in the medium-distance schooling area are both high, the number of in-coming students resident students are equal, and there is an obvious interaction between schools and residences. However, the out-going school attendance rate in the long-distance schooling area is very high and the in-going school attendance rate is very low. On the whole, the out-going school attendance rate is very low in the short-distance schooling area, while the in-going school attendance rate is very high, which shows that it ranks highest when it comes to schooling, followed by the medium-distance schooling area, and the long-distance schooling area is the weakest. Therefore, students mainly attend schools in the urban central area, but there is no attraction in the marginal area; therefore, it is imperative to improve the quality of education in the marginal area.

Table 2. In-going and out-going school attendance rates in different areas.

\begin{tabular}{ccccccc}
\hline & \multicolumn{3}{c}{ Out-Going Rate/\% } & \multicolumn{2}{c}{ In-Going Rate/\% } \\
\cline { 2 - 6 } & Kindergartens & $\begin{array}{c}\text { Primary } \\
\text { Schools }\end{array}$ & $\begin{array}{c}\text { Secondary } \\
\text { Schools }\end{array}$ & Kindergartens & $\begin{array}{c}\text { Primary } \\
\text { Schools }\end{array}$ & $\begin{array}{c}\text { Secondary } \\
\text { Schools }\end{array}$ \\
\hline $\begin{array}{c}\text { Short-distance } \\
\text { schooling area }\end{array}$ & 12.58 & 4.80 & 5.65 & 33.86 & 34.53 & 34.15 \\
$\begin{array}{c}\text { Medium-distance } \\
\text { schooling area }\end{array}$ & 89.04 & 95.54 & 96.13 & 77.65 & 77.11 & 51.23 \\
$\begin{array}{c}\text { Long-distance } \\
\text { schooling area }\end{array}$ & 82.93 & 91.39 & 87.05 & 58.39 & 58.54 & 55.75 \\
\hline
\end{tabular}

There are a number of study centers mainly distributed in the urban central area north of Hunhe River. The distribution of kindergartens in the school centers is relatively balanced and there are school centers in urban peripheral areas such as Shenbei New District and Sujiatun District, while primary schools and secondary schools are concentrated in the urban central area, such as Shenhe District, Heping District, Dadong District, and Tiexi District. This area represents the oldest area of urban development, with good economic conditions, dense population, complete educational facilities, and abundant educational resources. It is worth noting that Vanke Garden and Changbai on the south bank of the Hun River are important parts of the "golden corridor and silver belt" structure of Shenyang, with rich educational resources.

\section{Conclusions and Discussion}

\subsection{Conclusions}

As an important component of urban spatial structure, the school-residence spatial relationship is related to social equity, and travel between them has an important influence on urban traffic, which has a far-reaching impact on urban functionality. In this study, mobile phone signaling data was used to explore travel-to-school distance characteristics and travel-to-school spatial structure for the month of May 2018 in Shenyang. The main conclusions are as follows:

(1) Student density presents a truncated decreasing power law distribution with travel-to-school distance for basic education. At the beginning, the density of students decreases rapidly, but when the distance reaches a certain value, the decline rate tends to be gentle. When the density of students reaches $80 \%$, the distance corresponds to the scope of schooling attraction of students. The average distance between the residence and kindergarten, primary school, and middle school in Shenyang is $5.52 \mathrm{~km}, 5.54 \mathrm{~km}$, and $5.55 \mathrm{~km}$ respectively, which indicates that the overall level of travel is relatively low and the problem of long distance to school is quite serious.

(2) The distance threshold of travel for kindergartens is $1.30 \mathrm{~km}$, and that for primary schools and secondary schools is $1.50 \mathrm{~km}$. According to the threshold of distance and scope of attraction, urban school-residence spatial structure is divided into a core area, peripheral area, and marginal area. The distance increases from the core area to the marginal area, indicating obvious "short-medium-long distance" characteristics in the layout structure. The residence-school ratio decreased from the core area to the marginal area, and the residence-school spatial matching also decreased in turn. 
(3) Dominant travel-to-school flow is from urban peripheral and marginal areas to the core area, and partly from marginal areas to peripheral areas. The 7th level is mainly the connection between the key schools and the important adjacent residential areas in the urban core area. The 6th level is mainly for key schools and important residential areas within the urban core area and between the urban core area and the peripheral area. The 5th level runs through the core area and marginal area. The urban core is the most attractive schooling area, while the marginal area is the least attractive.

(4) The pattern of travel-to-school is multicentered, forming a number of study centers, which are mostly concentrated in the central urban areas, such as Shenhe District, Heping District, Dadong District, and Tiexi District. These are the traditional political, economic, educational, and cultural centers, and the oldest and most mature areas of Shenyang. In addition, the study centers are mainly located north of the Hun River.

\subsection{Discussion}

China has already entered a new era of socialist development and the social education demand has transformed from the need for "quantity" to the pursuit of "quality". As an important part of urban public service facilities, the uneven distribution of educational facilities is one of the influencing factors of urban residential space differentiation. In addition, educational facilities are characterized by high frequency, irreplaceability, and periodicity, which have a great influence on living and the daily commute of people. Schools provide a highly regular, almost mechanical order, with regular hours of attendance from Monday to Friday. Due to the intensive traffic flow between schools and residence, there is an impact on urban traffic during a fixed period of time every day. In addition, residential and education spaces also have an important impact on the functional layout of the surrounding land. Furthermore, they are a part of the surrounding supporting layout and influence the surrounding housing prices, while stimulating consumption and promoting economic growth. With the development of urbanization and suburbanization, urban built-up areas are expanding. The contradiction between the supply and demand of educational facilities is becoming more and more obvious, which is mainly manifested in the imbalance of space distribution of educational facilities, especially of high-quality educational resources. Therefore, solving the contradiction between supply and demand of education and optimizing the school-residence structure has become an important issue in urban planning. Data generated from mobile signaling data provides a new paradigm for researchers and planners to understand urban systems and urban spaces. The emergence of this data shifts the focus on urban planning from long-term strategic planning to short-term thinking about how cities work and are managed. It can better identify the characteristics of urban school-residence structure and provide a basis for optimization of urban spatial structure, layout of educational facilities, and road traffic planning.

According to the results of our research, the basic education facilities in Shenyang are concentrated and distributed in the central city, and the number of educational facilities in marginal areas is relatively small, especially in newly developed areas. The uneven distribution of educational facilities in Shenyang has resulted in a lot of students who live in the urban marginal area traveling to schools in the central city. In addition, the average distance between the residence and kindergarten, primary school, and middle school in Shenyang is $5.52 \mathrm{~km}, 5.54 \mathrm{~km}$, and $5.55 \mathrm{~km}$ respectively. Therefore, to optimize the school-residence layout in Shenyang in the future, it is necessary to focus on updated planning and to improve the supporting infrastructure to guide educational facilities to agglomerate reasonably in the marginal areas. The scale of educational facilities and residential land in urban core areas needs to be effectively controlled and the construction of educational facilities in peripheral and marginal areas needs to be increased in order to achieve shorter travel distances. In view of the current spatial living and studying situation and the characteristics of travel-to-school distance, we propose the following differentiation strategies. Firstly, according to the residential distribution characteristics of students, adjust the spatial distribution of educational resources. Efforts will be made to increase investment in new urban development areas such as Hunnan District, Sujiatun 
District, and Shenbei New Area, and to form a spatial pattern of educational resources that is in harmony with the urban spatial structure, population concentration, distribution of school-age children, and industrial development. Secondly, promoting the adjustment of the distribution of high-quality educational resources, and the diffusion of high-quality educational resources in central areas to suburbs and remote areas through co-operation and branch schools, and promoting the equitable allocation and equalization of high-quality educational resources. Thirdly, according to the law of students' travel-to-school distance, the service radius of educational facilities should be controlled within the threshold of the school distance. The quality of education in the border areas should be improved, attracting students from the border area to attend nearby schools. This would reduce the phenomenon of cross-regional schooling in pursuit of educational quality, thus reducing wasteful commuting costs and easing use of road traffic resources. A public transport system and public transport development policy should be implemented to alleviate traffic congestion, especially the morning and evening peak resulting from travel to and from schools.

Based on the mobile phone signaling data of Unicom users in Shenyang for the month of May 2018, this paper discussed the relationship between student density and travel-to-school distance, and obtained the attraction range and distance threshold of schooling. In addition, it discussed the relationship between living and studying, summarized the characteristics of Shenyang's travel-to-school pattern, and put forward strategies for the improvement of the spatial distribution of living and studying. This study can be used as a reference for other cases. In future research, we will discuss the characteristics of the residence-school structure and what causes this structure, which will provide a reference for the optimization of residence-school spatial structure and promote the enrollment of students in the vicinity.

Author Contributions: Conceptualization, C.X.; methodology, Y.W.; formal analysis, D.M.; data curation, D.M.; writing—original draft preparation, D.M.; writing—review and editing, X.F.; visualization, Y.W.; supervision, C.X.; funding acquisition, C.X.

Funding: This research was funded by National Natural Science Foundation (NSF) of China, grant number: No.41871162; 41801153; 41801108 .

Conflicts of Interest: The authors declare no conflict of interest.

\section{References}

1. Lu, M.; Sun, C.; Zheng, S. Congestion and Pollution Consequences of Driving-to-School Trips: A Case Study in Beijing. Transp. Res. D Transp. Environ. 2017, 50, 280-291. [CrossRef]

2. Zheng, S.; Hu, W.; Wang, R. How Much is a Good School Worth in Beijing? Identifying Price Premium with Paired Resale and Rental Data. J. Real Estate Financ. Econ. 2015, 53, 184-199. [CrossRef]

3. Horner, M.W.; O’Kelly, M.E. Is non-work travel excessive? J. Transp. Geogr. 2007, 15, 411-416. [CrossRef]

4. Yang, H.K.; Gustafsson, J.E. Causes of educational segregation in Sweden-school choice or residential segregation. Educ. Res. Eval. 2016, 22, 23-44. [CrossRef]

5. Howard, E. Garden Cities of to-Morrow; Sonnenschein \& Co: London, UK, 1902.

6. O'Brien, R.J. Model for planning the location and size of urban schools. Socio-Econ. Plan. Sci. 1969, 2, 141-153.

7. Morrill, R.L. Efficiency and equity of optimum location models. Antipode 1974, 6, 41-46. [CrossRef]

8. Malczewski, J.; Jackson, M. Multicriteria spatial allocation of educational resources: An overview. Socio-Econ. Plan. Sci. 2000, 34, 219-235. [CrossRef]

9. Yi, J.; Chou, K.L.; Yung, L.; Zhang, J. Public Housing, School Segregation, and Children's Education: Evidence from Hong Kong. Front. Econ. China 2015, 10, 414.

10. Siegelhawley, G. City Lines, County Lines, Color Lines: The Relationship between School and Housing Segregation in Four Southern Metro Areas. Teach. Coll. Rec. 2013, 115, 194-219.

11. Odis, J.J. Still Separate, Still Unequal: The Relation of Segregation in Neighborhoods and Schools to Education Inequality. J. Negro Educ. 2014, 83, 199-215. [CrossRef] 
12. Lareau, A. Commentary: The American Tradition of Inequality: Neighborhoods and Schools. Am. Educ. Res. J. 2017, 54, 190S-192S. [CrossRef]

13. Lange, W.; Alves, F. Spatial Index of Educational Opportunities: Rio de Janeiro and Belo Horizonte. Procedia Soc. Behav. Sci. 2011, 21, 287-293. [CrossRef]

14. Wu, Q.; Zhang, X.; Waley, P. Jiaoyufication: When gentrification goes to school in the Chinese inner city. Urban Stud. 2016, 53, 3510-3526. [CrossRef]

15. Wu, Q.; Cheng, J.; Chen, G.; Hammel, D.J.; Wu, X. Socio-spatial Differentiation and Residential Segregation in the Chinese City based on the 2000 Community level Census Data: A Case Study of the Inner City of Nanjing. Cities 2014, 39, 109-119. [CrossRef]

16. Yang, Z.S.; Su, Z.L.; Ding, Y.; Cheng, Z. The external effect of jiaoyufication upon urban space. Hum. Geogr. 2018, 33, 60-67. (In Chinese)

17. Fack, G.; Grenet, J. When do Better Schools Raise Housing Prices? Evidence from Paris Public and Private Schools. J. Public Econ. 2010, 94, 59-77. [CrossRef]

18. Ries, J.; Somerville, T. School Quality and Residential Property Values: Evidence from Vancouver Rezoning. Rev. Econ. Stat. 2010, 92, 928-944. [CrossRef]

19. Agarwal, S.; Rengarajan, S.; Sing, T.F.; Yang, Y. School Allocation Rules and Housing Prices: A Quasi-experiment with School Relocation Events in Singapore. Reg. Sci. Urban Econ. 2016, 58, 42-56. [CrossRef]

20. Imberman, S.A.; Lovenheim, M.F. Does the Market Value Value-added? Evidence from Housing Prices after a Public Release of School and Teacher Value-added. J. Urban Econ. 2016, 91, 104-121. [CrossRef]

21. Klesges, R.C.; Eck, L.H.; Hanson, C.L.; Haddock, C.K.; Klesges, L.M. Effects of obesity, social interactions, and physical environment on physical activity in pre-schoolers. Health Psychol. 1990, 9, 435-449. [CrossRef]

22. Broberg, A.; Sarjala, S. School travel mode choice and the characteristics of the urban built environment: The case of Helsinki, Finland. Transp. Policy 2015, 37, 1-10. [CrossRef]

23. DiGuiseppi, C.; Roberts, I.; Li, L.; Allen, D. Determinants of car travel on daily journeys to school: Cross sectional survey of primary school children. BMJ 1998, 316, 1426-1428. [CrossRef] [PubMed]

24. Yang, Y.; Ivey, S.S.; Levy, M.C.; Royne, M.B.; Klesges, L.M. Active travel to school: Findings from the Survey of US Health Behavior in School-Aged Children, 2009-2010. J. Sch. Health 2016, 86, 464-471. [CrossRef]

25. Bouzarth, E.L.; Forrester, R.; Hutson, K.R.; Reddoch, L. Assigning students to schools to minimize both transportation costs and socioeconomic variation between schools. Socio Econ. Plan. Sci. 2018, 64, 1-8. [CrossRef]

26. Müller, S.; Tscharaktschiew, S.; Haase, K. Travel-to-school mode choice modelling and patterns of school choice in urban areas. J. Transp. Geogr. 2008, 16, 342-357. [CrossRef]

27. Larsen, K.; Gilliland, J.; Hess, P.; Tucker, P.; Irwin, J.; He, M. The influence of the physical environment and socio-demographic characteristics on children's mode of travel to and from school. Am. J. Public Health 2009, 99, 520-526. [CrossRef]

28. Andersson, E.; Malmberg, B.; Östh, J. Travel-to-school Distances in Sweden 2000-2006: Changing School Geography with Equality Implications. J. Transp. Geogr. 2012, 23, 35-43. [CrossRef]

29. Cheng, L.; Chen, C.; Xiu, C.L. Excess kindergarten travel in Changchun, Northeast China: A measure of residence-kindergarten spatial mismatch. J. Transp. Geogr. 2017, 60, 208-216. [CrossRef]

30. Boussauw, K.; van Meeteren, M.; Witlox, F. Short trips and central places: The home- school distances in the Flemish primary education system (Belgium). Appl. Geogr. 2014, 53, 311-322. [CrossRef]

31. Easton, S.; Ferrari, E. Children's travel to school-The interaction of individual, neighbourhood and school factors. Transp. Policy 2015, 44, 9-18. [CrossRef]

32. Marique, A.F.; Dujardin, S.; Teller, J.; Reiter, S. School commuting: The relationship between energy consumption and urban form. J. Transp. Geogr. 2013, 26, 1-11. [CrossRef]

33. Ji, Y.; Zhou, J.X. Planning Methods of Basic Public Services Under Diversified Demands: A Case Study of Home-school Isochronal Spatial Structures of Beijing Pupils. Urban Dev. Stud. 2017, 24, 53-61. (In Chinese)

34. Huang, J.; Levinson, D.; Wang, J.; Jin, H. Job-worker spatial dynamics in Beijing: Insights from Smart Card Data. Cities 2019, 86, 83-93. [CrossRef]

35. Briand, A.S.; Côme, E.; Trépanier, M.; Oukhellou, L. Analyzing year-to-year changes in public transport passenger behaviour using smart card data. Transp. Res. Part C Emerg. Technol. 2017, 79, 274-289. [CrossRef] 
36. Cai, H.; Jia, X.; Chiu, A.S.F.; Hu, X.; Xu, M. Siting public electric vehicle charging stations in Beijing using big-data informed travel patterns of the taxi fleet. Transp. Res. Transp. Environ. 2014, 33, 39-46. [CrossRef]

37. Ferreira, N.; Poco, J.; Vo, H.T.; Freire, J.; Silva, C.T. Visual exploration of big spatio-temporal urban data: A study of New York city taxi trips. Vis. Comput. Graph. 2013, 19, 2149-2158. [CrossRef] [PubMed]

38. Chen, C.; Ma, J.; Susilo, Y.; Susilo, Y.; Liu, Y.; Wang, M. The promises of big data and small data for travel behavior (aka human mobility) analysis. Transp. Res. Part C Emerg. Technol. 2016, 68, 285-299. [CrossRef]

39. Zhong, G.; Yin, T.; Zhang, J.; He, S.; Ran, B. Characteristics analysis for travel behavior of transportation hub passengers using mobile phone data. Transport 2018, 3, 1-24. [CrossRef]

40. Lee, W.K.; Sohn, S.Y.; Heo, J. Utilizing mobile phone-based floating population data to measure the spatial accessibility to public transit. Appl. Geogr. 2018, 92, 123-130. [CrossRef]

41. Manfredini F, Pucci P, Tagliolato, P. Toward a systemic use of manifold cell phone network data for urban analysis and planning. J. Urban Technol. 2014, 21, 39-59. [CrossRef]

42. Sagl, G.; Delmelle, E.; Delmelle, E. Mapping Collective Human Activity in an Urban Environment Based on Mobile Phone Data. Cartogr. Geogr. Inf. Sci. 2014, 41, 272-285. [CrossRef]

43. Zhang, P.; Zhou, J.; Zhang, T. Quantifying and visualizing jobs-housing balance with big data: A case study of Shanghai. Cities 2017, 66, 10-22. [CrossRef]

44. Zhou, X.; Yeh, A.G.O.; Yue, Y. Spatial variation of self-containment and jobs-housing balance in Shenzhen using cellphone big data. J. Transp. Geogr. 2018, 68, 102-108. [CrossRef]

45. Jiang, B.; Liu, X. Scaling of geographic space from the perspective of city and field blocks and using volunteered geographic information. Int. J. Geogr. Inf. Sci. 2012, 26, 215-229. [CrossRef]

(C) 2019 by the authors. Licensee MDPI, Basel, Switzerland. This article is an open access article distributed under the terms and conditions of the Creative Commons Attribution (CC BY) license (http://creativecommons.org/licenses/by/4.0/). 